\title{
Nitrogen doped germania glasses with enhanced optical and mechanical properties
}

\author{
Storgaard-Larsen, Torben; Poulsen, Christian; Leistiko, Otto
}

Published in:

Journal of The Electrochemical Society

Link to article, DOI:

$10.1149 / 1.1837752$

Publication date:

1997

Document Version

Publisher's PDF, also known as Version of record

Link back to DTU Orbit

Citation (APA):

Storgaard-Larsen, T., Poulsen, C., \& Leistiko, O. (1997). Nitrogen doped germania glasses with enhanced optical and mechanical properties. Journal of The Electrochemical Society, 144(6), 2137-2142.

https://doi.org/10.1149/1.1837752

\section{General rights}

Copyright and moral rights for the publications made accessible in the public portal are retained by the authors and/or other copyright owners and it is a condition of accessing publications that users recognise and abide by the legal requirements associated with these rights.

- Users may download and print one copy of any publication from the public portal for the purpose of private study or research.

- You may not further distribute the material or use it for any profit-making activity or commercial gain

- You may freely distribute the URL identifying the publication in the public portal

If you believe that this document breaches copyright please contact us providing details, and we will remove access to the work immediately and investigate your claim 
21. W. Müller-Markgraf and M. J. Rossi, Rev. Sci. Instrum., 61, 1217 (1990).

22. V. Ilderem and R. Reif, This Journal, 135, 2569 (1988).

23. T. Sunada, T. Yasaka, M. Takakura, T. Sugiyama, S. Miyazaki, and M. Hirose, Jpn. J. Appl. Phys., 29, L2408 (1990).

24. M. A. Mendicino, Ph.D. Thesis, University of Illinois at Urbana-Champaign (1994).

25. W. K. Chu, H. Kroutle, J. W. Mayer, H. Muller, M. A Nicolet, and K. N. Tu, Appl. Phys. Lett., 25, 454 (1974).

26. J. Engqvist, C. Myers, and J.-O. Carlsson, This Journal, 139, 3197 (1992).

27. R. Ditchfield, M. A. Mendicino, and E. G. Seebauer, ibid., 143, 266 (1996).

28. K. Saito, T. Amazawa, and Y. Arita, ibid., 140, 513 (1993).

29. D. W. Williams, E. Coleman, and J. M. Brown, in Proceedings of the Workshop on Tungsten and Refractory Metals for VLSI Applications, R. S. Blewer, Editor, p. 125, MRS, Pittsburgh, PA (1985).

30. L. A. Clevenger, J. M. E. Harper, C. Cabral, C. Nobili, G. Ottaviani, and R. Mann, J. Appl. Phys., 72, 4978 (1992).

31. A. Bouteville, A. Royer, and J. C. Remy, This Journal, 134, 2080 (1987).
32. R. P. Southwell and E. G. Seebauer, J. Vac. Sci Technol., A13, 221 (1995)

33. H. de Lanerolle, B. Kim, L. Moser, Y. Zheng, D. Steiner, and J. Berg, J. Electron. Mater, 19, 1185 (1990).

34. R. P. Southwell and E. G. Seebauer, Surf. Sci., 329, 187 (1995).

35. Z. Ma, L. H. Allen, and D. D. J. Allman, J. Appl. Phys., 77, 4384 (1995).

36. M. A. Mendicino and E. G. Seebauer, Surf. Sci., 277, 89 (1992).

37. S. M. Gates, C. M. Greenlief, D. B. Beach, and P. A Holbert, J. Chem. Phys., 92, 344 (1990)

38. M. A. Mendicino and E. G. Seebauer, This Journal, 140, 1786 (1993).

39. S. M. Gates, C. M. Greenlief, S. K. Kulkarni and H. H. Sawin, J. Vac. Sci. Technol., A8, 2965 (1990).

40. M. A. Mendicino and E. G. Seebauer, Appl. Surf. Sci., 68, 285 (1993).

41. P. Gupta, P. A. Coon, B. G. Koehler, and S. M. George, Surf. Sci., 249, 92 (1991)

42. R. P. Southwell and E. G. Seebauer, Appl. Surf. Sci., In press.

43. E. G. Seebauer and C. E. Allen, Prog. Surf. Sci., 49, 265 (1995)

44. M. S. Chandrasekharaiah, J. L. Margrave, and P. A. G. O'Hare, J. Phys. Chem. Ref. Data, 22, 1459 (1993).

\title{
Nitrogen Doped Germania Glasses with Enhanced Optical and Mechanical Properties
}

\author{
T. Storgaard-Larsen \\ Brüel \& Kjoer A/S, DK2850 Norum, Denmark \\ C. V. Poulsen ${ }^{a}$ \\ Optoelectronics Research Centre, University of Southampton, Southampton SO17 1BJ, England \\ O. Leistiko \\ Microelectronics Centre, Technical University of Denmark, DK2800 Lyngby, Denmark
}

\begin{abstract}
A new type of ultraviolet photosensitive germanium doped glass has been developed for use in the fabrication of optical waveguide structures. By adding ammonia to the source gases during a plasma enhanced chemical vapor deposition of these glasses, ultraviolet induced refractive index changes of up to $3.5 \times 10^{-3}$ have been obtained. Although this is, to the best of our knowledge, a record for germanium doped silica films not photosensitized by hydrogen loading, our results show that even larger changes in the refractive index can be induced. Stable glasses with refractive indexes from 1.460 to 1.518 have been formed throughout the composition range from 0 to $30 \%$ germanium by including ammonia in the deposition process. Not only is it possible to increase the photosensitivity, but it is also possible to control stress in these films. Depending on the deposition and annealing conditions, these glass films can be made to exhibit a range of stress from compressive to low tensile when deposited on silicon wafers.
\end{abstract}

Because of its excellent optical properties, germanium doped glass is the most commonly used core material for low loss optical fibers. Interest in this material increased when it was shown by Hill et al., ${ }^{1}$ that it was photosensitive, i.e., that permanent changes of the refractive index could be made by irradiating this glass using ultraviolet (UV) light. The first UV written Bragg grating in an optical fiber was also made by Hill in 1978. 'The final breakthrough, however, was first seen when Glenn et al. ${ }^{2}$ demonstrated in 1988 that Bragg gratings could be written in optical fibers by exposing the side of the fiber to a two beam UV-light interference pattern. By varying the angle of incidence of the two beams, gratings having different periods could be made. The applications of photoinduced gratings include wavelength filters working as strain and

a C.V.P. was a member of the research team at the Microelectronics Centre when this work was performed. temperature sensors, dispersion compensating filters, and fiber laser mirrors. Despite great efforts, the mechanisms responsible for the photosensitivity of Ge-doped glasses is still not fully understood.

Recently, UV writing has also become a topic of great importance in thin film planar waveguide technology. Simplification of the process of planar waveguide fabrication, by direct UV laser writing of buried planar waveguide structures, including couplers, and splitters in three-layer $\mathrm{SiO}_{2} / \mathrm{GeO}_{2}-\mathrm{SiO}_{2} / \mathrm{SiO}_{2}$ glass films, ${ }^{3,4}$ could have a profound effect on the field of integrated optics. It should also be mentioned that the fabrication of planar waveguides employing photolithography and Ge-doped glasses also benefits from the use of UV writing techniques, in the realization of more advanced devices.

Only very few papers have been published on thin film processing of germanium doped glasses, however, in all 
honesty it should be noted that integrated optical devices based on flame hydrolysis deposited germanium doped glasses are already commercially available from PIRI. ${ }^{5}$ Nourshargh ${ }^{6}$ reports on fabrication of germanium doped planar waveguides using microwave plasma chemical vapor deposition (MPCVD) and Rastani et $a l^{7}$ report on low pressure chemical vapor deposition (LPCVD) of germanium doped oxides.

Both UV written ${ }^{3}$ and more typical buried planar waveguides based on plasma enhanced chemical vapor deposition (PECVD) Ge-doped glass have been demonstrated. ${ }^{8,9}$ Also, other groups have begun reporting on activities in thin film processing of PECVD germanium doped glasses. ${ }^{10}$

\section{Special Requirements for an Opto-Mechanical Sensor}

For this work the interest was in making an optomechanical accelerometer based on strain sensing by a UV light written Bragg grating in a planar waveguide bridge. ${ }^{11}$ To achieve a nondistorted mechanical frequency response and a high mechanical sensitivity it was necessary that the bridges, which were $1 \mathrm{~mm}$ in length, had a low tensile stress and small cross-sectional dimensions. Thus, a new type of germanium doped glass had to be developed. In order to enable fabrication of a functional device based on the cladding glass described in the article by StorgaardLarsen et al., ${ }^{11}$ our germanium doped glass had to fulfill the following requirements: (i) high refractive index, $>1.50$. The cladding glass (SiON100) reported in the previous paper, ${ }^{12}$ that seemed to be the best choice for our waveguide bridges, had a refractive index of 1.477 . In order to achieve low tensile stress without signs of cracking, the total thickness of the waveguide layer should not exceed 5 to $6 \mu \mathrm{m}$. For the wave to be well guided, at these, relative to the optical wavelength $(1.55 \mu \mathrm{m})$, small waveguide dimensions, a large index change $(0.02$ to 0.05$)$ between core and cladding is needed; ${ }^{13}$ (ii) low tensile stress: a core glass having high compressive stress would necessarily require a cladding glass having an even higher tensile stress, in order to achieve the required total stress, i.e., thermal stress + intrinsic stress, of the waveguide structure. Also, a nonuniform stress distribution in the cross section of the waveguide layer can cause unwanted birefringence. Earlier work has shown that the maximum stress (tensile) is obtained by annealing the glasses at approximately $800^{\circ} \mathrm{C}^{12}$ (iii) photosensitive; index modulation better than $5 \times 10^{-4}$ should be achievable; to fabricate the Bragg grating specified in the paper by StorgaardLarsen et al., ${ }^{11}$ an index change in the order of $2 \times 10^{-3}$ is desired.

The typical index range that can be obtained with germanium doped oxide is between $1.46\left(\mathrm{SiO}_{2}\right)$ and 1.61 $\left(\mathrm{GeO}_{2}\right){ }^{7}$ However, our first requirement cannot be fulfilled with any known types of germanium doped glasses. Germanium doped glasses are known to be hydroscopic. At $\mathrm{GeO}_{2}$ concentrations exceeding $20 \%$, films annealed at temperatures around $800^{\circ} \mathrm{C}$ start becoming unstable, and tend to become water soluble, ${ }^{7,8}$ Hence, the upper limit of the index range that can be covered by germanium doping of high quality silica glasses is limited to about 1.48 to 1.49 .

It is well known that slightly higher refractive indexes can be achieved in optical fibers by applying processing temperatures as high as $2000^{\circ} \mathrm{C} .^{14}$ Refractive indexes in the range of 1.50 are obtained at germanium concentrations of $25 \%$.

According to Miller et al., ${ }^{14}$ the thermal expansion coefficient of germanium doped glass increases linearly with the Ge concentration. At a germanium to silicon ratio of about $25 \%$, a match to silicon is achieved $(2.6 \mathrm{ppm})$. By matching the coefficients of thermal expansion of germanium doped glass to that of silicon, it is possible to eliminate the effects of thermal stress and, thus, the achievement of tensile stress in the glass will depend only on the intrinsic stress. ${ }^{12}$

In this paper we describe the development of a new type of PECVD germanium doped glass capable of fulfilling our special requirements.

\section{Experimental}

A load locked parallel-plate STS (E-type) PECVD reactor was used for deposition of the glasses in this work. The reactor can be driven both by a low frequency $(380 \mathrm{kHz})$ $\mathrm{RF}$ power supply and a high frequency (13.56 MHz) RF power supply. The reactor contains two parallel 10 in. diameter electrodes separated by a distance of $22 \mathrm{~mm}$. The lower electrode, which supports the substrate, is grounded. A schematic of the PECVD reactor is shown in Fig. 1. A more detailed description of the PECVD reactor can be found in the thesis by Mattsson. ${ }^{15}$

Annealing was carried out in a Tempress furnace at temperatures ranging from 700 to $1100^{\circ} \mathrm{C}$ in a $\mathrm{N}_{2}$ atmosphere. To avoid thermal shocks, slow loading/unloading $(10 \mathrm{~mm} / \mathrm{min})$ was applied and dummy wafers were used in both ends of the quartz furnace boat. Warm-up, from the standby temperature of $700^{\circ} \mathrm{C}$, was done at a speed of $10 \mathrm{~K} / \mathrm{min}$ while cooling was done at $4 \mathrm{~K} / \mathrm{min}$. Also, argon was tested as the ambient atmosphere, but no significant changes in film stresses and refractive indexes were measured when using this more expensive alternative.

The total mechanical stress of the films at room temperature was determined with a Tencor surface profiler by measuring the curvature of the silicon wafer before and after the deposition and after each of the following thermal annealing steps. For stress measurements, film thicknesses of more than $2 \mu \mathrm{m}$ were preferred to ensure high accuracy. The reproducibility of the stress measurements were within $\pm 1 \mathrm{MPa}$. Finally, the applied sign convention is positive $(+)$ when tensile stress and $(-)$ when compressive. The measured stress $\left(\sigma_{t}\right)$ can be written as the sum of the intrinsic stress $\left(\sigma_{i}\right)$ related to deposition kinetics and the thermal stress $\left(\sigma_{\mathrm{th}}\right)$ attributed to difference of thermal expansion coefficients of film and the silicon substrate. ${ }^{12}$

The thickness and refractive index were measured with a prism coupler system ${ }^{15}$ capable of measuring the refractive indexes up to 1.52 with an accuracy better than $\pm 2 \times$ $10^{-4}$ and determining the thickness with an accuracy of $\pm 0.02 \mu \mathrm{m}$. The system which is operated at an optical wavelength of $632.8 \mathrm{~nm}$ is used on glass films thicker than $2 \mu \mathrm{m}$. Each film was measured at the center of the wafer, and in radial distances of 1 and $2.5 \mathrm{~cm}$ from the center. Four in. diam, 450 to $550 \mu \mathrm{m}$ thickness, single-side polished (100) silicon wafers were used as substrates during development of the PECVD glasses.

As mentioned earlier, standard low frequency PECVD germanium doped glasses become unstable at high germanium concentrations ( $>20$ to $25 \%$ ) indicating porosity and water solubility. ${ }^{7,8}$ Since high germanium concentrations would be needed in order to fulfill our special requirement for a high refractive index $(n>1.50)$, a new type of glass had to be developed for this project. In the previous paper, ${ }^{12}$ the effect of nitrogen doping on high frequency (13.56 MHz) PECVD $\mathrm{SiO}_{2}$ films was discussed. The silicon oxynitride films offered high refractive indexes and stresses (tensile), and low etch rates. Inspired by these interesting glass properties the attempt of developing a silicon/germanium oxynitride $\left(\mathrm{SiO}_{x} \mathrm{~N}_{y} \mathrm{H}_{z}-\mathrm{GeO}_{x} \mathrm{~N}_{y} \mathrm{H}_{z}\right)$ was initiated by adding ammonia to the gas mixture. The resulting process-

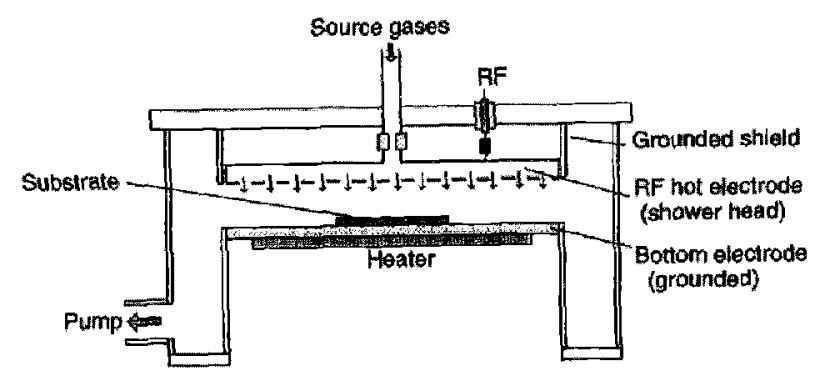

Fig. 1. Schematic of the parallel plate PECVD reactor. ${ }^{15}$ 
Table I. Processing conditions.

\begin{tabular}{lcc}
\hline Ge-doped glass & & Process conditions \\
\hline Flow, sccm & $\mathrm{SiH}_{4}$ & 12 to 17 \\
& $\mathrm{GeH}_{4}$ & 0 to 5 \\
& $\left(\mathrm{SiH}_{4}+\mathrm{GeH}_{4}\right)$ & 17 \\
& $\mathrm{~N}_{2}$ & 833 \\
$\mathrm{~N}_{2} \mathrm{O}$ & 1600 \\
$\mathrm{NH}_{3}$ & 0 to 400 \\
RF-power, W & if $380 \mathrm{kHz}$ & 380 \\
Pressure, mTorr & & 400 \\
Temperature, ${ }^{\circ} \mathrm{C}$ & & 300
\end{tabular}

ing conditions for the glasses are shown in Table I. Again, as for the processing conditions for silicon oxynitride given in our previous paper, ${ }^{12}$ the presence of $\mathrm{N}_{2}$ in the gas mixture results from changing from diluted to undiluted silane. The total flow of silane plus germane was kept constant at $17 \mathrm{sccm}$, in order to focus on effects related to changes in the germane to silane gas composition ratio. It should be mentioned that the adding of ammonia to the gas mixture lowers the partial pressures of the other gases due to an increase in the total gas flow.

\section{Results and Discussion}

Figure 2 shows the variation of the refractive index of nitrogen doped glasses annealed at $800^{\circ} \mathrm{C}$, as a function of the mole fraction of germane in the silane/germane gas mixture, which is kept at a total of $17 \mathrm{sccm}$. The ammonia flow is varied from 0 to $400 \mathrm{sccm}$. Apart from a few exceptions, the refractive index is seen to increase almost linearly with the mole fraction of germane. The sudden divergence from linearity at increasing germane mole fractions for $0 \mathrm{sccm} \mathrm{NH}_{3}$ flow, is due to the increase in porosity. Annealing the same glasses for $2 \mathrm{~h}$ at $1100^{\circ} \mathrm{C}$ (dashed curve), leads to a densification of the glasses, "re-establishing" a linear dependence between the refractive index and the molar concentration of germane. The intersection of the ordinate at a refractive index of 1.46 for ammonia flows in the range from 0 to $200 \mathrm{sccm}$, indicates that the nitrogen is only bonded to germanium. However, this is contradicted by the results of the films having higher ammonia flows. It is also interesting to note a nonlinear dependence of the refractive index on ammonia gas flow is seen when no $\mathrm{GeH}_{4}$ is added to the gas mixture. Finally, we call attention to the fact that a glass with a measured

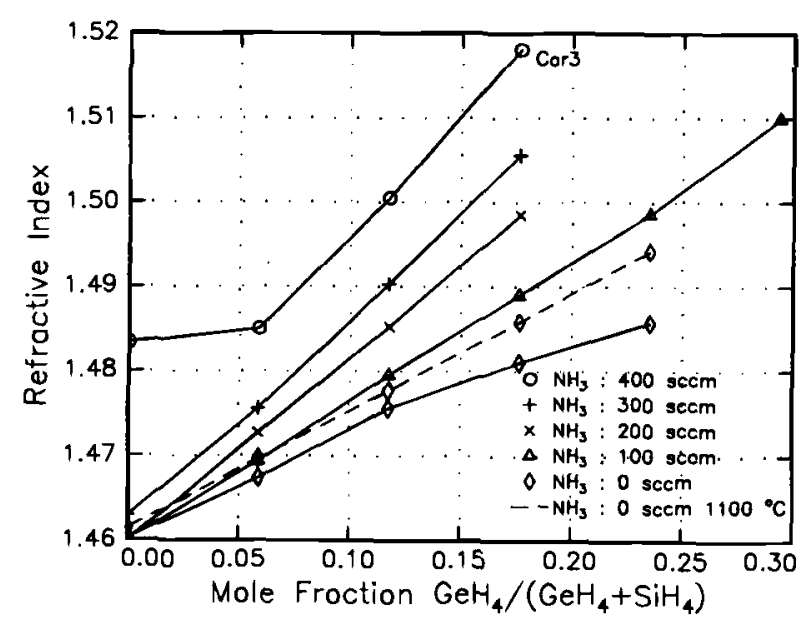

Fig. 2. The refractive index as a function of germane mole fraction at varying ammonia flows. Solid curves: annealing: $2 \mathrm{~h}$ at $800^{\circ} \mathrm{C}$; No. 590 - S95, No. S102 - \$105, No. TU34-TU37, No. S157, No. S160, No. S162 - S168. Dashed curve: annealing: 2 h at $800^{\circ} \mathrm{C}+2 \mathrm{~h}$ at $1100^{\circ} \mathrm{C}$, No. S157, S162 - S165. refractive index of 1.518 was obtained at germania and ammonia gas flows of 3 and $400 \mathrm{sccm}$, respectively. ${ }^{12}$

Figure 3 shows the refractive index $v s$. the ammonia flow for germane gas flows of 2 and $3 \mathrm{sccm}$. It appears that the refractive index depends more or less linearly on the ammonia flow for these processing conditions. Furthermore, the differences in gradients for the two curves supports the conclusion that the amount of nitrogen incorporated in the film depends on the content of germane in the gas mixture.

Figure 4 illustrates the total stress, as-deposited, and after $2 \mathrm{~h}$ of annealing, as a function of the germane for ammonia gas flows of 100 and $200 \mathrm{sccm}$. The stress is seen to increase with the content of $\mathrm{GeH}_{4}$ in the gas flow. This supports the assumption that the contribution from thermal stress is reduced when germanium is incorporated in the glass.

The total stress as a function of ammonia flow for germane flows of 2 and $3 \mathrm{sccm}$ is shown in Fig. 5. The total stress is seen to decrease almost linearly with the ammonia flow. Upon annealing at $800^{\circ} \mathrm{C}$, the influence of ammonia doping on the total stress becomes linear. The deviation from almost linear behavior of the curve representing the $3 \mathrm{sccm} \mathrm{GeH}_{4}$ film supports our conclusion that some of the films become porous if no ammonia is added to the gas mixture.

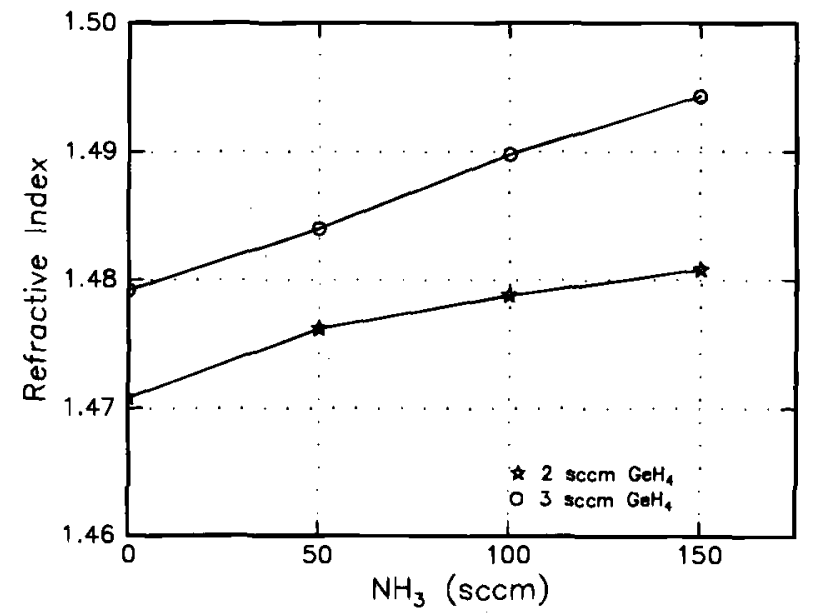

Fig. 3. The refractive index vs. ammonia flow at germane flows of 2 and $3 \mathrm{sccm}$ (= germane mole fractions of 12 and $18 \%$ ). Annealing: $2 \mathrm{~h}$ at $800^{\circ} \mathrm{C}$; No. $580-\mathrm{S} 83$, No. $585-$ S88.

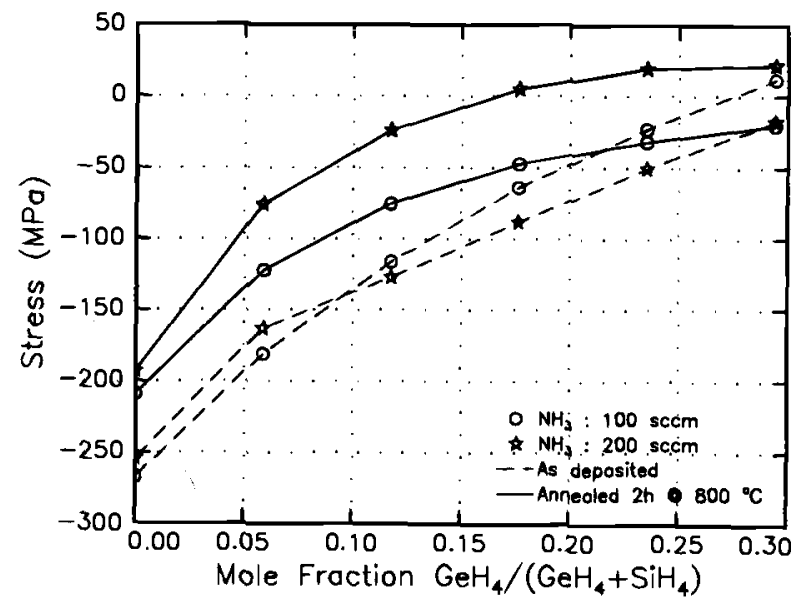

Fig. 4. The total stress as a function of germane mole fraction at ammonia flows of 100 and $200 \mathrm{sccm}$. Dashed curves: as-deposited, No. S90 - S95, No. S102 - S107. Solid curves: annealing: 2 h at $800^{\circ} \mathrm{C}$; No. 590 - S95, No. S102 - S107. 


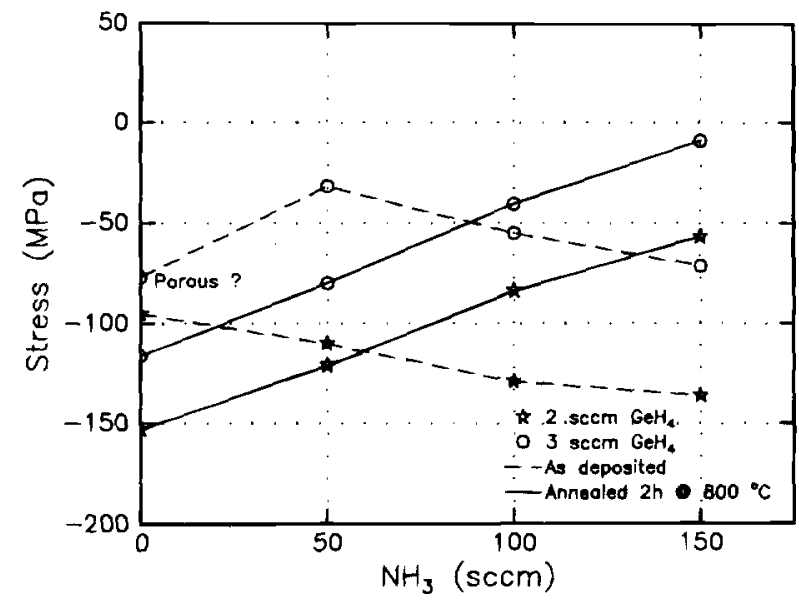

Fig. 5. The total stress vs. ammonia flow at germane flows of 2 and $3 \mathrm{sccm}$ (= germane mole fractions of 12 and $18 \%$ ). Dashed curves: as-deposited, No. 590 - 595, No. S102 - S107. Solid curves: annealing: $2 \mathrm{~h}$ at $800^{\circ} \mathrm{C}$; No. 590 - 595, No. 5102 - S107.

The potential of fabrication of films having a zero total stress, as-deposited, is clearly demonstrated with the results shown in the Fig. 4 and Fig. 5. Furthermore, the low stress levels, as-deposited, can be maintained after $2 \mathrm{~h}$ of annealing at $800^{\circ} \mathrm{C}$. These observations can be of major interest for so-called surface micromachining, where a low stress sacrificial layer between substrate and intended mechanical elements can be crucial.

The influence of the ammonia gas flow on the BHF etchrate of the films is shown in Fig. 6. Even small ammonia gas flows, of about $50 \mathrm{sccm}$, can change germanium doped films from presumably being porous, after $2 \mathrm{~h}$ of annealing at $800^{\circ} \mathrm{C}$, into films exhibiting etch rates below the level of thermally grown oxides $(750 \AA / \mathrm{min})$. The etch rates are seen to saturate at ammonia flows exceeding $100 \mathrm{sccm}$. At this level of ammonia flow, the BHF etch rate is seen to decrease with increasing germane gas flow ratio in the range that has been investigated ( 0 to $30 \%$ ). Nearly identical etch rates are achieved by annealing the films $2 \mathrm{~h}$ at $1100^{\circ} \mathrm{C}$ in a $\mathrm{N}_{2}$ atmosphere (see dashed curve), instead of adding ammonia to the gas mixture.

When annealing nitrogen doped films at $1100^{\circ} \mathrm{C}$, localized microscopic blistering effects were seen. At high ammonia levels, the blisters turned into circular holes and a deposition of material onto the neighboring wafer on the

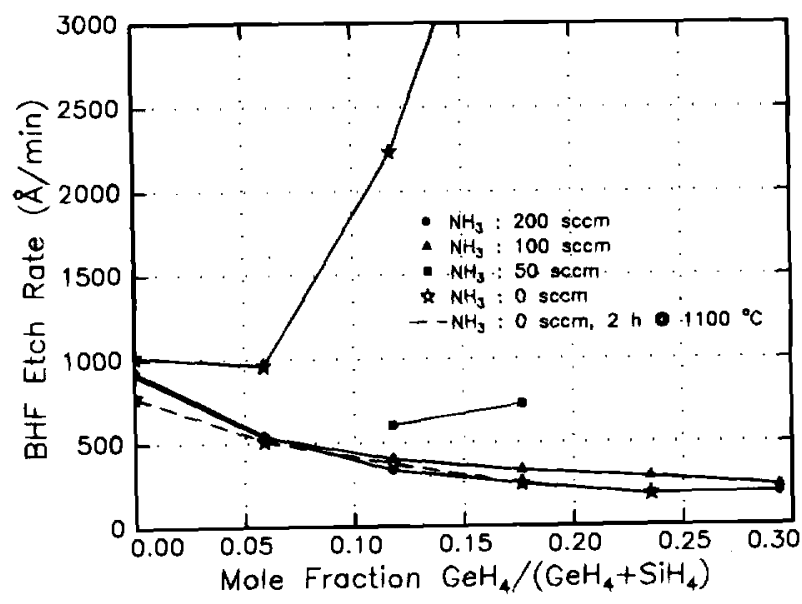

Fig. 6. BHF etch rate as a function of germane mole fraction at varying ammonia flows. Solid curves: annealing: $2 \mathrm{~h}$ at $800^{\circ} \mathrm{C}$; No. S81, No. 586, No. 590 - 595, No. 5102 - 5107, No. 5162 - 5167. Dashed curve: annealing: $2 \mathrm{~h}$ at $1100^{\circ} \mathrm{C}$; No. $5162-5167$. quartz boat (spacing $5 \mathrm{~mm}$ ), could be seen. Kern et $a l^{16}$ have observed similar phenomena on PECVD silicon nitride films upon annealing. The blistering was explained as being stress relief of films under compression and the plastic deformation is believed to be caused by outgassing of dissolved hydrogen.

At germane mole fractions exceeding about $10 \%$, experiments with BHF etching showed indications of inhomogeneities in the glasses. Ten minutes of BHF etching resulted in a coarse surface morphology which appeared white due to diffuse scattering of white light. The roughness was seen to increase with the germanium concentration. However, addition of ammonia to the gas mixture was found to improve the glass quality significantly. The amount necessary to prevent the films from appearing white after BHF etching increased with the germane gas flow. The low etch rates ( 200 to $300 \AA / \mathrm{min}$ ) imply that the roughness of the surface morphology on the etched films is not due to porosity. Furthermore, annealing at $1100^{\circ} \mathrm{C}$ $\left(\mathrm{NH}_{3}: 0 \mathrm{sccm}\right)$ did not reduce the problem.

Deposition rate.-The deposition rate was seen to increase with germane mole fraction, typically this ranges from 1200 to $1600 \AA / \mathrm{min}$.

Uniformity.-The uniformity of the glass thickness was seen to decrease with increasing amount of glass previously deposited on to the walls and electrodes of the deposition chamber. Thickness uniformity on a wafer ranged from 1 to $4 \%$, being best after a physical cleaning of the deposition chamber. The variations in refractive index across a wafer were within the uncertainty of the prism coupler system $\left( \pm 2 \times 10^{-4}\right)$.

Reproducibility.-The condition of the chamber did not seem to affect the refractive index significantly. Refractive indexes could be reproduced better than 0.001 if no major changes were made to the system, such as replacement of certain parts of the PECVD system. The condition of the chamber was monitored by deposition and characterization of test wafers.

\section{Photosensitivity}

The refractive index of germania doped glasses can be increased through absorption of visible or UV light. ${ }^{17-19}$ The relative index change is believed to be due to a redistribution of defects within the glass. Typically, the UV induced refractive indexes are categorized in two types. ${ }^{20}$ Type I is formed at low light intensities, type II, however, is formed at high light intensities, e.g., from a UV excimer laser, sometimes causing visible deformations of the glass. Type II index changes are thermally stable up to $800^{\circ} \mathrm{C}$ while type I begins to disappear at temperatures of about $300^{\circ} \mathrm{C}$.

Despite considerable research effort, the mechanisms responsible for the photosensitivity are not fully understood. It has been shown, ${ }^{17}$ that the UV photosensitivity depends to a large extent on the germanium concentration. The fact, that the glass quality becomes questionable at germanium concentrations exceeding 20 to $25 \%$, puts a constraint on the achievable photosensitivity. Typically, index changes in the order of $10^{-5}$ to $10^{-4}$ can be formed in standard germania doped optical fibers.

Different techniques to further enhance photosensitivity by deliberately generating defects in the glass have been demonstrated. ${ }^{17,18}$ By controlling the fabrication process, the concentration of the oxygen deficient germania defects $(\mathrm{GeO})$ can be increased, leading to an improvement of the photosensitivity. Hydrogen $\left(\mathrm{H}_{2}\right)$ loading of germania doped glasses, in high pressures (200 bar) or at elevated temperatures, has been used to achieve index changes as high as $0.011^{18}$ However, the long-term stability of refractive index changes formed by this technique is not acceptable, and transmission losses in the IR region of the waveguides increase significantly due to formation of hydroxyl groups $(\mathrm{OH})$ having a peak absorption at a wavelength of $1380 \mathrm{~nm}$. The broad $\mathrm{OH}$ absorption band also creates increased losses at $1.55 \mu \mathrm{m}$. Replacing hydrogen with the 
more expensive deuterium $\left(\mathrm{D}_{2}\right)$ is believed to reduce the formation of $\mathrm{OH}$. Finally, boron codoping of germania doped films has been used to enhance photosensitivity. It is suggested that boron promotes a stress relaxation effect in the glass.

For direct UV-writing of planar waveguides, the refractive index change should preferably be $5 \times 10^{-3}$ or higher. $^{4}$ This is in contrast to writing of Bragg gratings where $5 \times$ $10^{-4}$ is sufficient.

Measured UV induced index changes up to $2.5 \times 10^{-3}$ have previously been reported for hydrogen loaded PECVD germania doped oxides. ${ }^{3}$ Combining hydrogen loading and boron codoping, films formed by flame hydrolysis have exhibited index changes calculated to be $7.5 \times 10^{-3}{ }^{4}$

The silicon/germanium oxynitride films described in this paper obviously fulfilled our special requirements for high refractive indexes and tensile stresses. However the question remains: "How does nitrogen codoping, by adding ammonia to the gas mixture, affect the photosensitivity of germania doped PECVD glasses?"

Exposure of films to UV light from a $193 \mathrm{~nm}$ excimer laser resulted in surprisingly high index changes, which could be measured with the prism coupler system. Type A films and type $\mathrm{B}$ films, both processed with a $\mathrm{NH}_{3}$ flow of $400 \mathrm{sccm}$ and annealed at $800^{\circ} \mathrm{C}$, and both having refractive indexes of about 1.495 , were compared. The type A film was processed from the recipe shown in Table I, while the recipe of the type $B$ film differs from this in that the $R F$ power used was $800 \mathrm{~W}$ and the pressure was 600 mTorr The germane gas flows of the two films were 2 and $4 \mathrm{sccm}$, respectively. Table II show the process conditions for the two films as well as the measured refractive index changes $\Delta n$, achieved after UV exposures of $16 \mathrm{~min}$ which was equivalent to a total fluence of $4800 \mathrm{~J} / \mathrm{cm}^{2}$. The pulse energy was about $100 \mathrm{~mJ} /$ pulse at a pulse duration of $20 \mathrm{~ns}$ at 20 pulses/s, and the spot size was around $2 \times 20 \mathrm{~mm}$, giving an intensity of around $12 \mathrm{MW} / \mathrm{cm}^{2}$ at the surface of the glass film. Also, lower fluences were applied on the same wafer indicating that saturation does not occur at $4800 \mathrm{~J} / \mathrm{cm}^{2}$.

For a nonhydrogen loaded germania doped film the photoinduced index change of $3.5 \times 10^{-3}$ exhibited by the type A films must be considered very high. The type B film shows a lower index change despite a two times higher germane concentration in the gas phase.

It is known that the presence of ammonia in the gas mixture enhances the incorporation of hydrogen in ordinary PECVD silicon nitrides and oxynitrides. We might explain the photosensitivity by a high content of hydrogen due to the presence of ammonia in the gas mixture. In the hydrogen loading process, the physically dissolved hydrogen $\left(\mathrm{H}_{2}\right)$ first reacts with the glass during UV exposure and thereby forms defects in the glass. Since the exposure of our films to UV light takes place after an $800^{\circ} \mathrm{C}$ anneal in $\mathrm{N}_{2}$ we conclude that the $\mathrm{H}_{2}$ is more tightly bonded to the glass matrix than is the case with hydrogen doping.

An alternative hypothesis to explain the enhanced photosensitivity could be based on the presence of nitrogen in the films. Nitrogen alters the glass matrix, creating more absorption bands which might result in a higher degree of absorption of the UV photons again leading to a higher photosensitivity.

\section{Table II. Process conditions for the two films, A and B, along with the measured refractive index changes $\Delta \mathrm{n}$ achieved after UV ligh exposures having a total fluence of $4800 \mathrm{~J} / \mathrm{cm}^{2}$.}

\begin{tabular}{lcc}
\hline Glass type: & Type A & Type B \\
\hline $\mathrm{GeH}_{4} /\left(\mathrm{GeH}_{4}+\mathrm{SiH}_{4}\right)$ & $\approx 12 \%$ & $\approx 24 \%$ \\
$\mathrm{NH}_{3}$ flow, sccm & 400 & 400 \\
$\mathrm{RF}_{4}$ power, $\mathrm{W}$ & 380 & 800 \\
Pressure, $\mathrm{mTorr}$ & 400 & 600 \\
$\mathrm{UV}$ induced $\Delta n$ & $>3.5 \times 10^{-3}$ & $>1.8 \times 10^{-3}$
\end{tabular}

UV written multimode waveguides in three-layer glass film structures based on the type A glass, has shown propagation losses as low as $0.3 \mathrm{~dB} / \mathrm{cm}^{21}$

\section{Conclusions}

Addition of ammonia $\left(\mathrm{NH}_{3}\right)$ to a $\mathrm{GeH}_{4}-\mathrm{SiH}_{4}-\mathrm{N}_{2}-\mathrm{N}_{2} \mathrm{O}$ gas mixture in a PECVD reactor produced a new kind of silicon/germanium oxynitride glass.

The refractive index was seen to linearly depend on germane mole fraction $\left(\mathrm{GeH}_{4} /\left(\mathrm{SiH}_{4}+\mathrm{GeH}_{4}\right)\right)$ and ammonia flow. While typical Ge-doped glasses can have refractive indexes up to about 1.50 , without being water soluble, this new type of glass offers low loss, nonporous, low etch rate films having refractive indexes up to about 1.52. Adding ammonia to the gas mixture was seen to change films, which are presumably porous, into dense films exhibiting $\mathrm{BHF}$ etch rates below the level of thermally grown oxide, which are more typical of $\mathrm{SiON}$ or $\mathrm{Si}_{3} \mathrm{~N}_{4}$. Also the roughness of the glass surface after etching in $\mathrm{BHF}$ was seen to improve with the ammonia gas flow.

The total stress of films annealed at $800^{\circ} \mathrm{C}$ was seen to increase with the germane mole fraction and the ammonia flow. As-deposited films which were stress-free or having low tensile stress were demonstrated. Annealing these films at $800^{\circ} \mathrm{C}$ only caused modest changes of the total stress. This glass might be a candidate as a sacrificial layer in surface micromachining.

UV-radiation of type A glass at a wavelength of $193 \mathrm{~nm}$ at room temperature produces permanent changes in the refractive index in excess of $3.5 \times 10^{-3}$. To our knowledge, this is the highest UV-induced index change ever reported on a Ge-doped glass film which has not been hydrogen loaded.

Manuscript submitted Aug. 13, 1996; revised manuscript received March 25, 1997.

Brüel \& Kjaer A/S assisted in meeting the publication costs of this article.

\section{REFERENCES}

1. K. O. Hill, Y. Fujii, D. C. Johnson, and B. Kawasaki, Appl. Phys. Lett., 32, 647 (1978).

2. W. H. Glenn, G. Meltz, and E. Snitzer, U.S. Pat 4,725,110 (1988)

3. M. Svalgaard, C. V. Poulsen, A. Bjarklev, and $O$. Poulsen, Electron. Lett., 30, 1401 (1994).

4. G. D. Maxwell and B. J. Ainslie, ibid., 31, 95 (1995).

5. Photonics Integration Research Inc, Sales brochure on planar waveguides (1993)

6. N. Nourshargh, E. M. Starr, and T. M. Ong, Electron. Lett., 25, 981 (1989).

7. S. Rastani and A. Reisman, This Journal, 137, 1288 (1990).

8. J. O. Gulløv, M.S. Thesis, Mikroelektronik Centret, The Technical University of Denmark (1995)

9. B. Rose, M.S. Thesis, Mikroelektronik Centret, The Technical University of Denmark (1995).

10. M. V. Bazylenko, M. Gross, P. L. Chu, and D. Moss, in Photosensitivity and Quardratic Nonlinearity in Glass Waveguides, Fundamentals and Applications, Vol. 22, p. 108, OSA, Portland, OR (1995)

11. T. Storgaard-Larsen, S. Bouwstra, and O. Leistiko, Sens. Actuators, A52, 25 (1996).

12. T. Storgaard-Larsen and O. Leistiko, This Journal, 144, 1505 (1997).

13. B. E. A. Saleh and M. C. Teich, Fundamentals of Photonics, John Wiley \& Sons, Inc., New York (1991).

14. Optical Fiber Telecommunications, S. E. Miller and A. G. Chynoweth, Editors, Academic Press, New York (1979).

15. K. E. Mattsson, Ph.D. Thesis, The Technical University of Denmark (1994).

16. W. Kern and R. S. Rosler, J. Vac. Sci. Technol., 14, 1082 (1977).

17. R. J. Campell and R. Kashyap, Int. J. Optoelectron., 9, $33(1994)$

18. D. L. Williams, B. J. Ainslie, R. Kashyap, G. D Maxwell, J. R. Armitage, R. J. Campell, and R. Wyatt, Proc. SPIE, 2044, 55 (1993) 
19. P. J. Lemaire and T. Erdogan, in Photosensitivity and Quardratic Nonlinearity in Glass Waveguides, Fundamentals and Applications, Vol. 22, p. 78, OSA, Portland, OR (1995).
20. P. St. J. Russell, J-L. Archaumbault, and L. Reekie, Physics World, pp. 41-46 (Oct. 1993).

21. C. V. Poulsen, T. Storgaard-Larsen, J. Hübner, and O. Leistiko, Electron. Lett., Submitted.

\title{
Deposition of Carbon-Rich Film during Etching of Aluminum and Aluminum Oxide Surfaces
}

\author{
J. Tonotani, S. Saito, and E. Nishimura \\ Toshiba Corporation, Manufacturing Engineering Research Center, 33 Shin-Isogo-cho, Isogo-ku, Yokohama 235, Japan
}

\section{ABSTRACT}

The deposition of carbon-rich film during etching of aluminum and aluminum oxide surface is studied. When the etching is carried out using a $\mathrm{BCl}_{3} / \mathrm{CH}_{3} \mathrm{OH}$ plasma excited in a parallel-plate magnetron-reactive ion etching reactor, deposits are observed on both aluminum and aluminum oxide surfaces. Analyses of the etched surfaces by x-ray photoelectron spectroscopy and Fourier transform infrared spectroscopy show that the deposits consist mainly of carbon with $\mathrm{C}-\mathrm{C}$ bonds. The analyses also suggest that the deposit is accumulated more easily on the aluminum surface than on the aluminum oxide surface when a small amount of $\mathrm{CH}_{3} \mathrm{OH}$ is added to $\mathrm{BCl}_{3}$. We consider that this difference in the deposition characteristics is dependent on the oxidation rate of the deposits due to the existence of oxygen on the etched surface. When we selectively etch aluminum oxide against aluminum as an application of these deposition phenomena, a good etching selectivity of more than ten is obtained.

\section{Introduction}

Due to the increase in the size of thin film transistor liquid crystal displays (TFT-LCDs) and in the number of pixels they contain, it has become necessary to use aluminum gate lines to overcome the problem of drive pulse delay. ${ }^{1-3}$ Aluminum, however, is difficult to handle because of its chemical and thermal instability; it can be eroded by acid or alkali and it can diffuse into an adjacent layer during heating. ${ }^{4}$ Therefore, when aluminum gate lines or signal lines are used in TFT-LCDs, they should be covered by an aluminum oxide layer to protect them from chemical and thermal damage. ${ }^{5}$ In order to pattern the double-layer gate lines by dry etching, the etching characteristics of both aluminum and aluminum oxide should be known in detail. Usually, in the fabrication of very large scale integrated (VLSI) circuits, gas containing chlorine is used in aluminum dry etching ${ }^{6,7}$ because aluminum reacts very easily with chlorine and the products $\mathrm{AlCl}_{3}$ and $\mathrm{Al}_{2} \mathrm{Cl}_{6}$ have high vapor pressures. However, this high reactivity of aluminum with chlorine often makes the etching process difficult. This is why polymer-generating species such as $\mathrm{CHF}_{3}$ and $\mathrm{CH}_{3} \mathrm{Cl}$ are added to gas containing chlorine when an anisotropic or tapered profile of etched aluminum is required. ${ }^{7}$ It has been reported that deposits which protect aluminum sidewalls from chlorine attack consist mainly of carbon and chlorine. ${ }^{7}$ However, the exact structures and deposition mechanisms of such polymers are not yet well understood. Only a few studies on the etching mechanism of aluminum oxide have been made. ${ }^{8}$

In this work, the deposit produced on aluminum and aluminum oxide surfaces when $\mathrm{BCl}_{3} / \mathrm{CH}_{3} \mathrm{OH}$ gas mixture is used as the etching gas is investigated. Because of the difficulty of analyzing the sidewalls, only the front surfaces, which were exposed to ion bombardment, are analyzed by x-ray photoelectron spectroscopy (XPS) and Fourier transform infrared spectroscopy (FTIR). The surface analyses of both aluminum and aluminum oxide and optical emission spectroscopy of $\mathrm{BCl}_{3} / \mathrm{CH}_{3} \mathrm{OH}$ plasma have led to a better understanding of the structure of the deposit and the deposition mechanism. Finally, we try to apply the deposition phenomenon to selective etching of aluminum oxide against aluminum.

\section{Experimental}

Test samples were prepared using 6 in. silicon wafers with $100 \mathrm{~nm}$ thick thermal silicon oxide layers. An alu- minum film 350 or $400 \mathrm{~nm}$ thick was deposited by magnetron sputtering (MCH-9000; ULVAC). Aluminum oxide samples were produced by anodic oxidation of the aluminum top surface to form $100 \mathrm{~nm}$ thick aluminum oxide layer. In anodic oxidation,, 910 an aqueous solution of a mixture of ammonium tartrate and ethylene glycol was used as the electrolyte,,$^{5,9,10}$ and the current density between the platinum cathode and aluminum anode was kept at about $1 \mathrm{~mA} / \mathrm{cm}^{2}$. The etching reactor shown in Fig. 1 is of a magnetron-reactive ion etching (RIE) type, where the magnetic field has a strength of about $200 \mathrm{G}$ immediately beneath the magnet and about $50 \mathrm{G}$ immediately above the electrode to which a radio frequency $(\mathrm{RF})$ is applied. The wafer was cut into $3 \times 3 \mathrm{~cm}$ pieces, and $\mathrm{BCl}_{3} / \mathrm{CH}_{3} \mathrm{OH}$ gas mixture was used as the etching gas. In this study, only the gas flow rate ratio of $\mathrm{BCl}_{3} / \mathrm{CH}_{3} \mathrm{OH}$ was varied. The process pressure, the applied $\mathrm{RF}(13.56 \mathrm{MHz})$ power and the powered electrode temperature were kept constant at $2.0 \mathrm{~Pa}$, $200 \mathrm{~W}$ (corresponding power/electrode area ratio is 1.5 $\mathrm{W} / \mathrm{cm}^{2}$ ) and $20^{\circ} \mathrm{C}$, respectively. The etched depth was measured using a step measurement tool (Dektak; Veeco

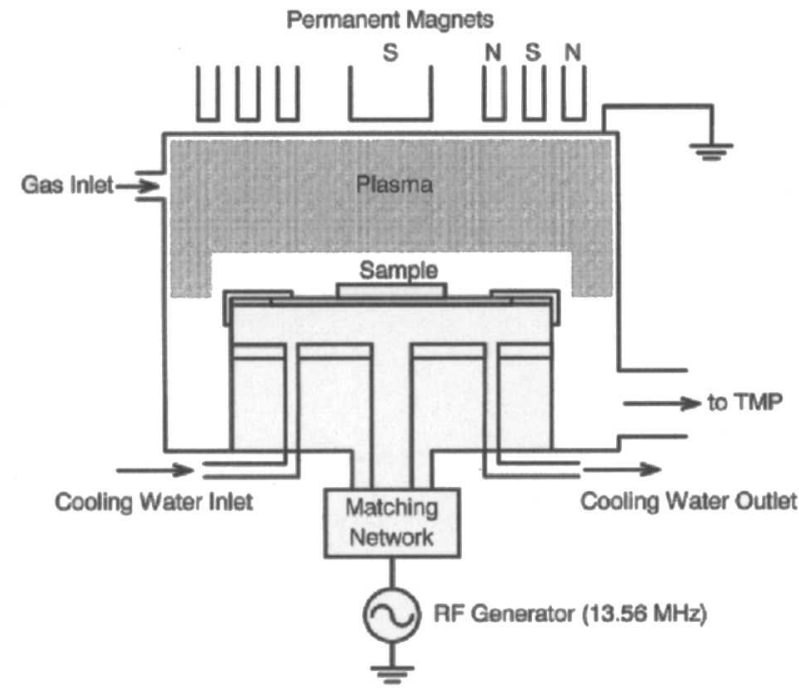

Fig. 1. Schematic diagram of etching reactor. 